\title{
As diplomatas bissau-guineenses por elas mesmas: obstáculos ao Ingresso e à permanência na cơrreira diplomática
}

Bissau-Guinean female diplomats by themselves: obstacles to admission and permanence in the diplomatic career

Las diplomáticas bisauguineanas por si mismas: obstáculos para la admisión y permanencia en la carrera diplomática

Naentrem Sanca ${ }^{1}$

Enzo Lenine ${ }^{2}$

DOI: $10.5752 /$ P.1809-6182.2020v17n2p48

Recebido em: 01 de junho de 2020 Aceito em: 21 de outubro de 2020

\begin{abstract}
Resumo
Quais os obstáculos vivenciados pelas mulheres bissau-guineenses para o ingresso e a permanência na carreira diplomática na República da Guiné-Bissau? Analisamos, por meio de entrevistas, os obstáculos materiais e simbólicos enfrentados pelas mulheres diplomatas de Guiné-Bissau na carreira.
\end{abstract}

Palavras-chave: Mulheres na diplomacia. Diplomacia africana. Mulheres africanas.

\begin{abstract}
What are the obstacles Bissau-Guinean women face prior to and upon admission to the diplomatic career in the Republic of Guinea-Bissau? We analyse through in-depth interviews the material and symbolic obstacles faced by women diplomats in Guinea-Bissau.

Keywords: Women in diplomacy. African diplomacy. African women.
\end{abstract}

\section{Resumen}

¿Cuáles son los obstáculos que enfrentan las mujeres bisauguineanas antes y después de su admisión a la carrera diplomática en la República de Guinea-Bisáu? Analizamos a través de entrevistas los obstáculos materiales y simbólicos que enfrentan las mujeres diplomáticas en Guinea-Bisáu en la carrera.

Palabras clave: Mujeres en la diplomacia. Diplomacia africana. Mujeres africanas.

\footnotetext{
1 Naentrem Sanca é mestranda no Programa de Pós-Graduação em Relaçôes Internacionais da Universidade Federal da Bahia e egressa do curso de Relaçōes Internacionais da Universidade da Integração Internacional da Lusofonia Afro-Brasileira (UnilabMalês). Interessa-se pelos temas de feminismo africano, gênero e diplomacia, e feminismo nas RI.

2 Enzo Lenine é professor de Relaçôes Internacionais da Universidade da Integração Internacional da Lusofonia Afro-Brasileira (Unilab-Malês). Interessa-se pelos temas de feminismo nas RI, teoria política e modelagem matemática. ORCID: https://orcid. org/0000-0001-5280-4252
} 


\section{Introdução}

Nas décadas de 1960 e 1970, as mulheres bissau-guineenses se depararam com um dos eventos mais importantes não só para o seu destino, como também o de todo o território da colônia portuguesa de Guiné-Bissau. A luta de independência, que culmina com a fundação da República de Guiné-Bissau em 1973, resultou dos ativismos de guineenses e caboverdianos, unidos sob a bandeira da descolonização europeia na África. As mulheres, como membros indissociáveis de ambas as sociedades, participaram ativamente do processo de libertação, sendo reconhecidas pelo mérito de sua luta (FIGUEIREDO; GOMES, 2016; GOMES 2016).

Entretanto, as mulheres guerreiras viram-se excluídas da política bissau-guineense tão logo a independência se concretizou. No recém-fundado Estado, a política não era um lugar para elas, de modo que suas contribuiçôes na luta contra o colonialismo tornaram-se mais um capítulo a ser relembrado do que de fato um marco nas relaçóes de gênero da sociedade bissau-guineense. Passados mais de 40 anos, desde que a República de Guiné-Bissau passou a ser membro da comunidade de naçóes soberanas, a participação das mulheres na política e na burocracia não faz jus às suas contribuições de outrora. Embora em anos recentes o tema da igualdade de gênero e dos direitos das mulheres venha promovendo mudanças na sociedade e na política bissau-guineenses, desigualdades e hierarquias de gênero persistem.

Nesse contexto, um dos espaços político-burocráticos marcados pela baixa presença feminina é a diplomacia. Conduzida pelo Ministério dos Negócios Estrangeiros, Cooperação Internacional e Comunidades, a diplomacia bissau-guineense conta com 17 embaixadas e se caracteriza por ser um espaço eminentemente masculino. Poucas mulheres conseguem ingressar na carreira e exercê-la em caráter de igualdade frente a seus pares homens.

Este fenômeno, em si, não é exatamente uma particularidade de Guiné-Bissau. A diplomacia em outros lugares do mundo padece de um déficit de representatividade feminina, ${ }^{3}$ mesmo em países onde os debates e movimentos feministas têm uma tradição mais longa, como é o caso do Brasil (BALBINO, 2011; FRIAÇA, 2012; FRITSCHE, 2002). Em larga medida, a arena internacional segue sendo um espaço masculinizado, a despeito dos essencialismos que tal asserção carrega (MONTE, 2013; TICKNER, 2006), o que se reflete no perfil dos diplomatas, cônsules e embaixadores.

Nesse sentido, o presente artigo pretende investigar as vivências e experiências de diplomatas mulheres de Guiné-Bissau que ingressaram na carreira e exercem a profissão como representantes de seu país. Partimos, portanto, da seguinte pergunta de pesquisa: quais os obstáculos vivenciados pelas mulheres bissau-guineenses para o ingresso e a permanência na carreira diplomática na República de Guiné-Bissau? Por meio de entrevistas conduzidas com duas diplomatas bissau-guineenses, objetivamos compreender quais os incentivos e, principalmente, os constrangimentos, tanto materiais quanto simbólicos, que as mesmas experimentaram em sua jornada de ingresso e exercício da carreira. Por se tratarem de membros de um quadro reduzido de profissionais - ainda mais do gênero

\footnotetext{
3 A obra Gender and Diplomacy de Jennifer Cassidy (2017) aborda, sob uma perspectiva comparada, diversas questôes acerca não só do déficit de mulheres nas diplomacias mundiais, como também desafios institucionais pelos quais as mesmas passam.
} 
feminino -, suas vivências permitem identificar padrões das hierarquias de gênero que incidem sobre as diplomatas mulheres. Tais hierarquias criam trajetórias profissionais distintas daquelas percorridas pelos seus colegas homens: as diplomatas tendem a ocupar espaços subalternizados, que reforçam estereótipos de gênero e condicionam os espaços ocupados pelas mulheres (AGGESTAM; TOWNS, 2019).

$\mathrm{O}$ artigo está estruturado em quatro seçôes. Na primeira seção, apresentamos brevemente os marcos políticos dos movimentos e debates feministas em Guiné-Bissau, chamando a atenção para a história e a articulação conceitual com os temas de redistribuição, reconhecimento e representação tão caros às teorias políticas feministas. Em seguida, detalhamos a metodologia da investigação, especificando como e com quem foram realizadas as entrevistas em profundidade que capturam as vivências das diplomatas mulheres. Na terceira seção, apresentamos elementos destas entrevistas que permitem compreender os obstáculos vividos pelas diplomatas antes e depois do ingresso na carreira. Finalmente, na quarta seção, discutimos alguns apontamentos acerca dos entraves da participação feminina na diplomacia de Guiné-Bissau.

\section{Marcos políticos do feminismo em Guiné-Bissau}

Diferentemente da narrativa clássica do feminismo no Ocidente ${ }^{4}$, o desenvolvimento

\footnotetext{
4 Tradicionalmente, o feminismo ocidental é narrado pelas três ondas feministas (GARCIA, 2011; ZERILLI, 2006). Porém, a incompletude desta narrativa é frequente alvo de críticas de outras vertentes do feminismo, tais como o feminismo negro (DAVIS, 2016; HILL COLLINS, 2019) e os feminismos subalternos (BALLESTRIN, 2017; MENDOZA, 2018; SPIVAK, 2012). Para uma abordagem alternativa, focada em temáticas, ver Hawkesworth e Disch (2018).
}

do feminismo bissau-guineense está profundamente associado ao processo de descolonização e sua consequente luta pela independência. Enquanto os movimentos e a teoria feministas caminhavam, nas décadas de 1960 e 1970, para um aprofundamento dos debates da segunda onda, uma parcela significativa dos países africanos, dentre eles os Países Africanos de Língua Oficial Portuguesa (PALOP), enfrentava conflitos em suas lutas pela independência. Nesses contextos, em que a independência era a prioridade máxima das sociedades africanas, a participação das mulheres nos esforços de libertaçáo tornou-se uma necessidade, com implicaçôes para os movimentos feministas que emergiram neste momento e se desenvolveram nas décadas seguintes.

As agendas feministas africanas fundamentam-se em um diálogo crítico com os feminismos ocidentais, nomeadamente aqueles que emergem nos Estados Unidos e na Europa. Chaves conceituais como gênero, sororidade e sexualidade (apenas para mencionar algumas) são profundamente criticadas por pensadoras e pensadores feministas da África e da diáspora (AMADIUME, 1987; HILL COLLINS, 2019; HOOKS, 2019; OYEWÜMÍ, 2003; TAIWO, 2003). Ao trazerem suas perspectivas críticas sobre modalidades distintas de matriarcado e comunidade para o centro dos debates feministas, os estudos africanos subvertem as imagens correntes sobre os efeitos do passado colonial e da escravidáo transatlântica na constituição das sociedades do continente, apontando como o imperialismo de outrora e as concepçóes do feminismo global contemporâneos guardam similaridades na sua tentativa de relegar ao oblívio as relaçóes sociais autóctones e o lugar da mulher africana nas mesmas (OKOME, 2003; OYEWÙMÍ, 2003). 
O passado colonial de Guiné-Bissau responde por uma parcela significativa da estruturação da sociedade bissau-guineense, nomeadamente no que tange às relaçóes de gênero. Se a sociedade como um todo se encontrava em uma posição de subalternidade em relação à metrópole portuguesa, as mulheres bissau-guineenses padeciam de uma dupla relação de subordinação: à colonização e ao patriarcado (FIGUEIREDO; GOMES, 2016). Não por acaso, os movimentos de mulheres emergem não com o objetivo de enfrentar isoladamente as dimensóes da subalternidade, mas sim visando a reposicionar as bissau-guineenses nos diversos espaços sociais e políticos do país. Nesse sentido, a fundação da União Democrática das Mulheres da Guiné e de Cabo Verde (UDEMU) em 1961 marca, ainda que de forma limitada no que tange à amplitude da participação feminina, o estabelecimento e o desenvolvimento de agendas das mulheres no processo de independência e constituição do Estado bissau-guineense (GOMES, 2016).

Evidentemente, a UDEMU per se não subverteu as hierarquias de gênero na Guiné. Em primeiro lugar, a Uniấo carecia de representatividade da totalidade e, fundamentalmente, diversidade de mulheres bissau-guineenses. Como país essencialmente rural, a UDEMU enfrentou a dificuldade de incluir em seus quadros e suas agendas as mulheres que viviam no e do campo, compondo-se primariamente de mulheres com formação educacional e acadêmica. A marginalização das mulheres rurais (tabanka, como são denominadas em crioulo $)^{5}$ produziu um movi-

5 Segundo Costa (2014), o crioulo da Guiné-Bissau é língua formada nos séculos XV eXVI com a chegada dos colonizadores portugueses a Guiné-Bissau, e integrada à família linguística dos demais crioulos de origem portuguesa, da qual faz parte também o crioulo caboverdiano (ou Kabuverdianu). Embora náo seja a língua oficial de Guiné-Bissau, o crioulo é falado pela maioria da população, ao passo que o português, mesmo sendo oficial é falado por $13 \%$ dos bissau-guineenses. mento insensível à realidade destas mulheres, com profundas implicaçôes para as desigualdades de gênero observadas em Guiné-Bissau.

Em segundo lugar, a própria liderança do processo de independência compunha-se de homens da elite de Bissau. O Partido Africano da Independência da Guiné e Cabo Verde (PAIGC) centralizou a organização política da luta pela independência, e embora seu líder, Amílcar Cabral, ${ }^{6}$ advogasse a favor da participação feminina não só nos esforços de descolonização, como também nas esferas de poder, sua voz foi silenciada pelos demais membros do partido (ABDENUR, 2018; FIGUEIREDO; GOMES, 2016; GOMES, 2016). A exclusão política das mulheres - requeridas, apenas, durante a luta pela independência - permanece até a atualidade, incidindo não apenas na ausência das bissau-guineenses nas instituiçôes políticas, como também no silenciamento de suas agendas.

Nesse sentido, e na contemporaneidade, as demandas das mulheres bissau-guineenses encaixam-se em três dimensôes fundamentais da teoria política feminista, quais sejam: redistribuição, reconhecimento e representação (FRASER, 2007; PHILLIPS, 2011; YOUNG, 2000). ${ }^{7}$ Essa multidimensionalidade re-

6 Amílcar Cabral (1924-1973) nasceu em Bafatá no território da atual Guiné-Bissau e com 8 anos viajou para Cabo Verde, acompanhando a sua família. Escritor, poeta, político, agrônomo e teórico marxista, Cabral desempenhou papel fundamental na luta de independência de Guiné-Bissau e Cabo Verde (NEVES, 2017).

7 Entende-se por redistribuição a preocupação da teoria e dos movimentos feministas com a correção das desigualdades socioeconômicas que penalizam as mulheres, tais como salários menores, dificuldades de ingresso no mercado formal, menor número de oportunidades entre outros. O reconhecimento, por sua vez, trata das dimensões culturais da dominação masculina, especialmente por meio dos papéis, e das políticas de identidade associadas ao gênero. Finalmente, a representaçáo refere-se à questáo da presença feminina e vocalizaçáo das demandas das mulheres nos espaços e debates políticos. Para um debate sintético e crítico, ver Fraser (2007). 
fere-se às manifestaçôes das desigualdades de gênero que incidem sobre as bissau-guineenses. No que tange à dimensão socioeconômi$\mathrm{ca}$, apenas 50,5\% das mulheres é alfabetizada (INEGB, 2014). Ademais, 64,7\% da populaçáo vivem com menos de US $\$ 2,00$ por dia (INEGB, 2014), sendo as mulheres mais afetadas pela pobreza. No que tange à dimensão do reconhecimento, as desigualdades de gênero estabelecem padróes de exclusão com base em papéis a serem desempenhados pelas mulheres, bem como as sujeitam a práticas culturais que violam sua autonomia. ${ }^{8} \mathrm{~A}$ tradicional esfera da domesticidade, que reserva à mulher a casa e o cuidado dos familiares, restringe as possibilidades de acesso ao mercado formal e à política (FIGUEIREDO; GOMES, 2016).

Outrossim, os efeitos da colonização ainda se fazem presentes no âmbito das relaçôes étnicas, que estabelecem hierarquias com base naqueles que ocuparam um lugar privilegiado na interação com os colonizadores, incidindo, por sua vez, nas desigualdades de gênero de forma interseccional com a etnicidade (FIGUEIREDO; GOMES, 2016). Finalmente, persiste em Guiné-Bissau um déficit na representação das mulheres nos espaços de poder formais. Embora em 2018 o governo tenha aprovado uma lei de paridade para garantir uma representação mínima de 36\% das mulheres nas instituiçôes políticas, ainda se nota a ausência feminina em determinados espaços, como é o caso da diplomacia.

Neste contexto, as mulheres bissau-guineenses enfrentam obstáculos particulares no que tange ao leque de oportunidades de inte-

\footnotetext{
8 Uma das práticas culturais mais emblemáticas que afeta diretamente a autonomia das mulheres bissau-guineenses é a mutilação genital feminina. Segundo Abdenur, " $48 \%$ das população feminina foi sujeita à mutilação genital feminina e excisão" (ABDENUR, 2018, p. 5).
}

gração social e inserção no mercado e na política. Se em determinado momento da História recente de Guiné-Bissau a presença feminina foi desejável para viabilizar a independência do país, uma vez liberto e fundado o Estado bissau-guineense, as mulheres passaram a ser excluídas dos espaços de poder, seja nos cargos eletivos, seja nas burocracias de Estado e políticas públicas. Como consequência, obstáculos nas três dimensóes supracitadas dificultam não só o ingresso, como o exercício da diplomacia por diplomatas mulheres em Guiné-Bissau.

\section{Metodologia}

De forma a compreender os obstáculos às mulheres bissau-guineenses no pré- e pós-ingresso à carreira diplomática, conduzimos entrevistas em profundidade com duas diplomatas mulheres e um diplomata homem, todos atuantes no momento de realização desta pesquisa. Em Guiné-Bissau, coexistem dois tipos de diplomatas: por indicação política e de carreira. $\mathrm{O}$ diplomata político é aquele indicado pelo partido político no poder, mas que não tem necessariamente formação na área. Já o diplomata de carreira é aquele que possui formação na área de diplomacia e não é indicado pelo partido político. Segundo o diplomata de carreira entrevistado:

Quando falamos de embaixador de carreira ou diplomata de carreira, ele é um funcionário efetivo do Ministério de Negócios Estrangeiros já há mais de 10 anos e que tem formação na diplomacia. Para ser diplomata ou embaixador, como requisito a pessoa tem de subir alguns degraus como adido, primeiro-secretário, segundo-secretário, conselheiro, ministro de segunda-classe e, finalmente, embaixador. Cumprido isso, é chamado de diplomata de carreira. Quanto ao diplomata político, ele é mais ligado ao partido político, e por isso vários países não o aceitam, tais como: Luxemburgo, Holanda e Suíça. 
No que tange às diplomatas entrevistadas, suas biografias são distintas. A entrevistada K., ${ }^{9}$ diplomata de carreira, possui uma trajetória peculiar no contexto mais amplo da educaçáo em Guiné-Bissau, vez que é uma pessoa com uma vivência no exterior. K. estudou em Portugal e fez a sua formação em diplomacia no Brasil, no Instituto Rio Branco. Já P., diplomata política, estudou o Ensino Primário na cidade de Farim e teve formação na área Técnica Industrial e Comércio de Bissau. Em 1966, foi para Portugal estudar o curso de Serviço Social. Em 1977, trabalhou como Responsável Adjunta na Direção dos Assuntos Sociais na Secretaria do Estado dos Combatentes da Liberdade da Pátria. Foi também Ministra de Estado, ocupando, em determinado momento, o cargo de embaixadora. Por se tratar de uma diplomata política, sua indicaçáo ao cargo foi feita pelo ex-presidente Malam Bacai Sanha.

As entrevistas com as diplomatas foram realizadas em Guiné-Bissau no período de 26 de fevereiro a 17 de março de 2019. As duas mulheres diplomatas pertencem, cada uma, às categorias supracitadas. Após as entrevistas, mantivemos contato com as diplomatas para apontamentos complementares. As conversas foram gravadas em formato .mp3, realizadas em criolo, traduzidas e transcritas para o português.

O roteiro de perguntas da entrevista buscou compreender os diversos significados dos obstáculos sociais e, mais precisamente, de gênero antes e depois do ingresso na carreira. As perguntas orientaram-se, sem menção direta, pela questão de pesquisa. Na seção seguinte, são apresentados fragmentos que evidenciam

9 Embora as diplomatas e o diplomata entrevistados tenham expressado não haver impedimentos na revelação de seus nomes, optamos por preservar a confidencialidade de suas identidades, tendo em vista os eventos políticos em Guiné-Bissau. esses obstáculos. Eles são articulados em torno de uma narrativa suplementada com uma discussão sobre os problemas de gênero que incidem sobre a participação feminina na diplomacia guineense.

Vale ressaltar a ausência de dados qualitativos e quantitativos suplementares para conferir apoio aos achados desta pesquisa. O quantitativo de mulheres diplomatas representando a República de Guiné-Bissau não está disponibilizado nos meios oficiais, nomeadamente, no site do Ministério dos Negócios Estrangeiros, da Cooperação e das Comunidades. ${ }^{10}$ Estimativas não oficiais indicam que 5,88\% das 17 embaixadas mantidas por Guiné-Bissau sejam chefiadas por mulheres, ao passo que 5,00\% dos seus consulados seriam chefiados por consulesas. As duas diplomatas que participaram das entrevistas fazem parte desse conjunto pequeno de mulheres no ministério, havendo se disponibilizado para fornecer informaçôes sobre suas trajetórias e vivências.

\section{As diplomatas por elas mesmas}

Nesta seção, analisamos as entrevistas visando a compreender como os obstáculos de gênero incidem sobre a presença feminina no corpo diplomático bissau-guineense. $\mathrm{Na}$ primeira parte, tratamos dos obstáculos antes do ingresso na carreira diplomática. $\mathrm{Na}$ segunda, discutimos os obstáculos uma vez que a diplomata já se encontra dentro do serviço diplomático.

10 Os autores, com apoio institucional da Unilab, reiteradamente solicitaram ao Ministério dos Negócios Estrangeiros, da Cooperação e das Comunidades da República de Guiné-Bissau informaçóes sobre o quantitativo atual e na série histórica dos diplomatas bissau-guineenses, identificados por gênero e data de ingresso. Os dados, porém, não foram fornecidos. 


\section{Obstóculos Pré-ingresso}

Independentemente da forma de ingresso na carreira diplomática - se por indicação política ou por aprovação em exames de admissão -, um dos principais obstáculos enfrentados pelas mulheres bissau-guineenses é de ordem estrutural, qual seja, o baixo nível de escolaridade. Segundo dados do Instituto Nacional de Estatística de Guiné-Bissau (2017), a situação das mulheres é precária: enquanto a taxa de alfabetização dos homens entre 15 e 24 anos foi de 70,4\% em 2014, a taxa para mulheres na mesma faixa etária e no mesmo período foi de $50,5 \%$. Ademais, apenas $20,4 \%$ da população concluiu o Ensino Médio em 2014 (INEGB, 2017). ${ }^{11}$ Ainda no que tange aos dados socioeconômicos, na sociedade guineense as mulheres constituem a camada mais pobre, principalmente em famílias chefiadas pela mulher (MARTINS et al., 2013). Segundo o Relatório sobre a Situação de Direitos Humanos na Guiné-Bissau:

A disparidade de gênero é mais do que manifesta no sistema nacional do ensino, na medida em que, se as proporçóes de raparigas e de rapazes são quase idênticas a nível do ensino de base elementar (nos quatro primeiros anos), não é o caso para os outros níveis de ensino. Com efeito, a partir do ensino de base complementar $\left(5^{\circ}\right.$ e $6^{\circ}$ anos) e, até ao ensino superior, a taxa das raparigas é apenas de 40\%. (MARTINS et al., 2013, p. 65)

Não por acaso, uma das entrevistadas, a diplomata política P., relata a diferença na forma que se educam a mulher e o homem em Guiné-Bissau como causa importante para a baixa presença feminina no corpo diplomático. Segundo ela, as mulheres são subordi-

11 Para dados mais detalhados sobre outros indicadores educacionais, ver Silva et al. (2016, p. 119). nadas por uma educação de domesticidade, e poucas tiveram oportunidade de obter uma educação formal. Portanto, a educação formal (ou falta dela) é um obstáculo forte para as mulheres ingressarem na diplomacia, como relata a diplomata:

Eu digo que existe ainda fraca participação das mulheres na carreira diplomática, porque ainda temos poucas mulheres formadas nesta área. Se formos ver a taxa de analfabetismo, encontraremos uma taxa maior das mulheres analfabetas mais do que dos homens, entáo isso já é um obstáculo para termos mulheres na diplomacia. Mesmo que hoje estejamos vendo algumas melhorias, ainda é pouco. Logo, este aspecto marca muito as impossibilidades para as mulheres, que elas vão enfrentar até chegarem ao nível de serem aceitas como uma pessoa capacitada, competente e igual a um homem. Uma das críticas do gênero é que o problema não é uma mulher, mas a questão intelectual, de formar mulheres e homens da mesma forma. Assim, todas as coisas têm que ser partilhadas sem hierarquia. Então, este fato é lamentável, porque existe diferença na educação e até hoje persiste. Felizmente, hoje existem várias ONGs, com parceria com o Estado, se posicionando acerca desta questão, a fim de ajudar na educaçáo e formação das mulheres. Portanto, fico feliz em ver que as mulheres estão tendo voz e vez. Uma coisa é ter voz, outra é ter vez.

Ainda no que tange ao pré-ingresso, um dos obstáculos fundamentais é que algumas mulheres desistem da carreira por entenderem a diplomacia como um lugar dos homens, impróprio para elas. As poucas referências de outras mulheres neste lugar retroalimentam este fato, como atestam as estimativas da proporçáo de embaixadoras e consulesas na diplomacia bissau-guineense apresentadas na seção anterior.

Outro obstáculo que impede as mulheres de se inserirem na diplomacia refere-se às duas categorias de diplomata no país, quais sejam: 
diplomatas políticos e diplomatas de carreira. Ambas as formas excluem as mulheres, porém a categoria que resulta da indicação do partido político tende a ser mais excludente, vez que os partidos dificilmente escolhem ou indicam mulheres para assumir a diplomacia. Por isso, não é surpresa que o corpo diplomático da Guiné-Bissau apresente uma baixa presença feminina, vez que ainda não é acessível para uma mulher a inserção não só por meio do ingresso na carreira, mas também no espaço mais amplo dos partidos políticos. Como resultado da falta de representatividade na esfera diplomática, as mulheres têm menos chances de influenciar as normas criadas e de desconstruir a visão masculinizada sobre a esfera (AGGESTAM; TOWNS, 2019). ${ }^{12}$

Nota-se, portanto, que os problemas socioeconômicos influenciam diretamente nas oportunidades de obtenção de educação formal, requisito fundamental para o ingresso na carreira diplomática. Essa situação é corroborada pelo fato de as duas diplomatas entrevistadas nesta pesquisa provirem de famílias com renda alta, conseguindo preencher os requisitos educacionais do cargo. Porém, apesar de suas características diferenciadas, seus relatos apontam para desigualdades de gênero que superam a dimensão socioeconômica. $\mathrm{O}$ elemento de reconhecimento também incide como fator de hierarquização de gênero, principalmente no exercício da carreira.

12 Aggestam e Towns (2018, p. 3-4) apontam que o espaço diplomático é profundamente generificado. As normas e práticas da diplomacia conferem determinados roteiros de comportamentos a depender do gênero. Elas apontam, ainda, que a presença cada vez maior em algumas academias diplomáticas (como é o caso da Suécia) (NIKLASSON; ROBERTSON, 2018) têm produzido alteraçôes na condução da política externa ao subverter esses roteiros generificados por meio do próprio questionamento das noções de masculinidade e feminilidade.

\section{Obstáculos na Correira}

Uma vez que uma mulher supere os desafios estruturais e individuais de acesso à carreira diplomática, interpóem-se novos obstáculos no exercício diário da profissão. Estes assumem diversas formas, em geral mais sutis na perspectiva das entrevistadas, mas que se constituem como formas de hierarquizar a presença feminina na diplomacia bissauguineense. Como relata a entrevistada K.:

Bem, você sabe que no nosso país se verificam muito os problemas de gênero em todas as esferas e os problemas socioeconômicos afetam mais as mulheres do que os homens. Vou te falar uma coisa, temos várias mulheres que prestaram concurso, mas o maior problema é a permanência delas aqui. Têm muitas mulheres com formação superior e com mais capacidade do que muitos homens, mas estão estagiando há mais de 6 anos ${ }^{13}$.

Percebe-se no relato que um dos principais desafios na relação com os diplomatas homens é o do reconhecimento do mérito e das qualificaçóes das mulheres. $\mathrm{O}$ tratamento como estagiária, em que são desempenhadas funções típicas de secretária, ${ }^{14}$ revela uma disparidade no exercício da profissáo profundamente marcada pela clivagem de gênero. $O$ estágio de cinco ou seis anos apresenta-se, portanto, como um possível tratamento diferenciado em comparação ao dado a homens que ingressam pelo mesmo

13 Esse tratamento diferenciado evoca um episódio em campo com uma funcionária do Ministério que se recusou a dar entrevista. Segundo ela, sua vida se resumiu a estagiar e sua recusa se justificou pela seguinte fala: "Não vou dar entrevista, porque não me consideram diplomata".

14 Ao longo das entrevistas, as diplomatas transpareceram o desconforto com funçóes que mais lembram as de uma secretária ocupada de agenda e questóes logísticas de seus superiores, do que de fato funçôes arquetípicas da diplomacia, tais como elaboração da política externa e negociaçóes internacionais. 
processo. ${ }^{15}$ Nesse sentido, este primeiro obstáculo demonstra-se uma ferramenta de exclusão e de discriminação das mulheres nesse espaço.

Porém, o tratamento diferenciado e subalterno não se limita apenas ao exercício das funçôes de diplomacia, mas também às possibilidades de ascensão na carreira. Um dos mais flagrantes e evidentes resultados das discriminaçóes de gênero é a baixa nomeação de mulheres ao cargo de embaixadoras. As razóes são variadas, desde o fato de a mulher ser casada, ou pura e simplesmente pelo fato de se tratarem de mulheres, supostamente impróprias pelo seu gênero para ocupar um cargo de tamanha envergadura política. Podemos observar isso no trecho abaixo, relatado por K.:

Comecei como adido, depois subi para primeira-secretária e em seguida a segunda-secretária. Havia homens que entraram depois de mim, mas que foram nomeados como embaixadores antes de mim. Existe essa diferença, mas o importante é que eu não desisti e consegui chegar lá, mesmo depois de enfrentar vários obstáculos. Espero que as próximas mulheres que querem seguir a carreira não passem pelo que eu passei. Na verdade, tenho a certeza de que elas já estão tendo dificuldades: temos poucas mulheres diplomatas. Hoje estamos lutando para mudar este cenário. Agora, o que queremos é uma colocaçáo fora do país como embaixadoras. Podemos exercer as nossas funçóes aqui, chegarmos ao nível de embaixadoras, mas para sermos consideradas mesmo como diplomatas, é necessário irmos para missôes fora. Nós, de carreira, fazemos como os militares: começamos de baixo até o cargo mais alto como embaixadora. Nosso desejo é representar Guiné-Bissau fora do país.

15 Como inexistem dados e informaçôes oficiais, e dado o caráter exploratório desta pesquisa, um comparativo com a trajetória dos homens não foi realizado no âmbito deste artigo. As dificuldades metodológicas apontadas no texto refletem não só os desafios de obter informaçóes das experiências vividas das mulheres diplomatas, como também dos próprios homens.
Fica evidente que as diplomatas guineenses passam dificuldades dentro da carreira não por incapacidade de articular, mas pelas marginalizaçóes institucionais, que ainda consideram a mulher como incapaz de resolver os problemas de Guiné-Bissau fora do território nacional. Esses obstáculos, por serem elementos que invisibilizam as mulheres neste espaço, eliminam potenciais referências de representatividade feminina na política e na burocracia, desincentivando consequentemente que outras mulheres aspirem à carreira.

Outro fator de ordem familiar que se evidencia como obstáculo na carreira é a dificuldade de o marido da diplomata encontrar trabalho no exterior. Os incentivos sociais para que o homem abandone seu emprego para acompanhar a mulher são menores, o que tornam episódicos os casos de saída de diplomatas mulheres para o exterior quando isso incide na vida profissional do marido. Já o oposto - que uma mulher desista do seu trabalho para acompanhar seu marido diplomata - é mais frequente. Neste sentido, várias vezes as mulheres não são mandadas em missão porque são casadas, ou a família não está em condiçōes de fazer toda a mudança. Por conta das injunçóes culturais e de gênero, algumas mulheres desistem de ir para missóes em prol do bem-estar da família, e não porque não têm vontade ou não queiram assumir o posto (BALBINO, 2011).

Quando questionadas sobre as preferências das diplomatas sobre trabalhar com chefes mulheres ou chefes homens e se, durante as suas vidas profissionais, tiveram mais chefes mulheres ou mais homens, as duas forneceram respostas distintas:

[K.]Quando comecei a trabalhar, tive duas mulheres que já foram minhas chefes. Trabalhei com Ilha Barba, que é inspiração para 
mim e foi a pessoa que mais me encorajou para seguir a carreira diplomática. Não tive problemas com ela. Também trabalhei com Eugenia Saldanha, dávamos-nos muito bem - aliás, até hoje temos um tratamento de respeito. Mas na minha carreira tive mais chefes homens, mas também foi tranquilo porque não me silencio, porque faço meu trabalho com profissionalismo. Já tive alguns problemas, mas enfrentei com rosto para cima e com humildade, mas para mim tanto faz mulher ou homem.

[P.] Eu sempre trabalhei com homens, mas quando eu estava trabalhando - porque parei agora - sempre trabalhei como chefe. Fui ministra várias vezes, nunca tive uma mulher como chefe, então não sei como seria, mas imagino que deva ser muito bom. Mas também os homens com quem trabalhei sempre me respeitavam, tudo era na base do profissionalismo.

Esses fragmentos revelam, embora ponderando a relação com os homens, uma preferência pelo trabalho com as mulheres. Ambas entrevistadas relatam a parca presença feminina nos espaços da diplomacia, especialmente na posição de chefia. Embora ambas afirmem que as relaçóes com chefes homens sempre se basearam no profissionalismo, existe uma expectativa de que, com uma mulher no comando, o trabalho seria positivo. No contexto dos tratamentos diferenciados, e contrapondo-se a eles, ambas partem do entendimento de que a mulher saberia lidar com os problemas como um homem. Nota-se, ainda, que a questão da representatividade como fonte de inspiração é um elemento forte no primeiro relato. Mesmo sem referenciar no mesmo tom, o segundo relato também sinaliza, por meio da expectativa positiva do trabalho chefiado por uma mulher, para a importância da representatividade feminina na diplomacia bissau-guineense. Embora o caso da segunda diplomata seja especial por ter ocupado o cargo de ministra, o fato de ambas relatarem a baixa presença feminina em cargos de chefia indica a existência de um teto de vidro para a trajetória das mulheres, que lhes dificulta ocupar cargos nas mais altas hierarquias, como, por exemplo, o de embaixadora.

\section{Mulheres na diplomacia bissqu-guineense: um balanço das experiências}

Percebeu-se, com os relatos, que as diplomatas bissau-guineenses ocupam um espaço dominado por homens. Esse achado, em si, não é uma particularidade do caso de Guiné-Bissau: as mulheres ainda ocupam poucos espaços na diplomacia (BALBINO, 2011; FRIAÇA, 2012). A própria arena internacional é um espaço que, tradicionalmente, é visto como de realização de ideais de masculinidade: as próprias lideranças de Estado e a diplomacia seriam funçóes imbuídas de uma essência masculina, aversa a características femininas associadas ao pacifismo e ao cuidado (TICKNER, 2006; ZALEWSKI, 1998). Não por acaso, o tratamento diferenciado dado às diplomatas mulheres evidencia o caráter masculinizado da carreira e do ministério, assim como age de forma a obstaculizar sua ascensão nos cargos e postos diplomáticos. O resultado é a já vista baixa presença de mulheres diplomatas.

Essa solidão no espaço de trabalho dificulta a articulação entre as mesmas. A inexistência de uma associação de mulheres diplomatas bissau-guineenses é um reflexo dessa solidão e, ao mesmo tempo, um entrave para promover mudanças na estrutura de gênero da carreira. Com uma associação, seria possível organizar as mulheres em torno de ideias e propostas para promover igualdade dentro do sistema. $\mathrm{Na}$ solidão de suas posiçôes, derrubar o sistema hierárquico que privilegia o homem pelo seu gênero é substantivamente dificultado. 
Para além dos obstáculos dentro da carreira, ainda existem entraves sociais para a inserção das mulheres nos espaços políticos e burocráticos. A persistência de desigualdades socioeconômicas que incidem com mais força sobre as mulheres dificulta a aquisição de educação formal, pré-requisito fundamental para o ingresso na carreira. Ademais, os constrangimentos culturais impostos pela ordem patriarcal acabam por limitar as bissau-guineenses a papéis associados à esfera doméstica (FIGUEIREDO; GOMES, 2016), tornando a possibilidade de ingressar na diplomacia uma opção não disponível para uma parcela significativa das mulheres do país. Associando-se este fato ao histórico de baixa representatividade política das mulheres em Guiné-Bissau no pós-independência (GOMES, 2016) - e que, mesmo com a lei de paridade, ainda não se alterou de forma consistente e universal nas esferas políticas -, verifica-se que as três dimensões supracitadas das teorias feministas (FRASER, 2007) são eivadas de desigualdades que penalizam as mulheres bissau-guineenses. Destarte, avançar na promoção de uma sociedade menos hierarquizada pelo gênero perpassa fomentar políticas públicas de redistribuição, reconhecimento e representação.

As entrevistas permitiram evidenciar o desejo das diplomatas de haver mais mulheres no corpo diplomático. Cada uma, a seu modo, relatou a preocupação de que as próximas mulheres não passem pelas dificuldades de reconhecimento na carreira. Como elas salientaram, as mulheres diplomatas bissau-guineenses dispóem das competências, capacidades e profissionalismo para o exercício da profissão. Os obstáculos produzidos por uma sociedade hierarquizada pelo gênero constituem os entraves para o devido reconhecimento das mulheres bissau-guineenses como aptas a ocupar os altos espaços da burocracia diplomática.

Nesse sentido, as entrevistas foram de suma importância para o entendimento das desigualdades de gênero na carreira diplomática bissau-guineense, que ainda subordina as mulheres a funções de secretária e, por outro lado, não são escolhidas para missões. Estas informaçóes só poderiam ser depreendidas por estas vivências, que, postas em conjunto, permitem compreender como as hierarquias de gênero operam na diplomacia bissau-guineense.

No que tange às biografias das entrevistadas, apesar das diferenças substantivas em suas trajetórias, notam-se vivências de desigualdades de gênero semelhantes. Apesar de os problemas de gênero não serem fixos ou terem só uma face, as diplomatas, a despeito de suas biografias, sofrem discriminação pelo próprio status de serem mulheres. Como se evidenciou nas entrevistas, duas mulheres de perfis e trajetórias distintos apontaram desigualdades criadas pelo gênero que, se não vivenciaram elas mesmas, ao menos presenciaram.

Por outro lado, durante as entrevistas, ficou evidente, em diferentes momentos, que o medo de represálias no emprego silenciou uma das entrevistadas em seus relatos sobre os problemas que as mulheres (ou, quiçá, ela mesma) enfrentam dentro do Ministério. Compreendemos que é um obstáculo, mas esse silêncio também é uma forma de resistência para permanecer naquele espaço. Também observamos durante as entrevistas que um dos obstáculos que algumas mulheres diplomatas enfrentam é o fato de serem solteiras. A opçáo por não contrair um matrimônio, considerada incompatível com as hierarquias de gênero na sociedade bissau-guineense, traz consequências variadas, como serem tachadas de rótulos pejorativos, 
que ferem sua honra e dignidade (por exemplo, serem automática e pejorativamente rotuladas de homossexuais); assim como tampouco serem escolhidas para missóes, porque são vistas como pessoas que não têm responsabilidade.

As entrevistas de campo, ao fim e ao cabo, não só enriqueceram o conhecimento acerca dos desafios e dos obstáculos que as mulheres bissau-guineenses enfrentam no ingresso na carreira e no exercício da própria diplomacia, como serve de inspiraçáo para que outras mulheres persigam a mesma e lutem para ampliar o acesso a este espaço. Parte desses resultados dialoga, ainda, com as experiências de outras mulheres em outros países no que tange à transversalidade do fenômeno de exclusão pelo gênero e das desigualdades e hierarquias que o mesmo enseja.

\section{Conclusão}

A diplomacia não é um espaço livre das hierarquias de gênero. A presença feminina nas carreiras diplomáticas de diversos países ainda é marcada por solidão, silêncio e ausências. Embora as organizaçóes internacionais e as lideranças dos Estados estejam cada vez mais conscientes da necessidade de avançar as agendas de igualdade de gênero e direitos da mulher, a baixa representatividade feminina nas burocracias internacionais - dentre elas, a diplomacia - é ainda uma realidade.

Ao analisarmos o caso bissau-guineense, buscamos evidenciar os obstáculos enfrentados pelas mulheres para ingressar na diplomacia e exercer suas funções como diplomatas. A partir das entrevistas, identificamos vivências semelhantes que revelam como as desigualdades de gênero operam mesmo ante às particularidades das biografias individuais. Além das dificulda- des materiais resultantes do contexto socioeconômico de Guiné-Bissau, dinâmicas associadas aos papéis de gênero verificam-se na experiência vivida das diplomatas.

Os relatos, à primeira vista, apontam para uma realidade preocupante dentro da diplomacia de Guiné-Bissau. Entretanto, a própria presença de mulheres rompe com as barreiras que lhes são impostas, e sua ascensão na carreira, ainda que lenta, quebra os tetos de vidro da diplomacia bissau-guineense. Ademais, no longo percurso dos movimentos feministas do país, a simples presença de referências femininas na carreira diplomática sinaliza para possibilidades profissionais para as novas geraçôes de mulheres bissau-guineenses, fortalecendo outras agendas de representação política e promoçáo de igualdade de gênero. As mulheres guerreiras de outrora vislumbram, nesses exemplos, novas possibilidades de emancipação e atuação política.

\section{Referências}

ABDENUR, A. E. Gender and Mediation in Guina-Bissau: The Group of Women Facilitators. Police brief: Igarapé Institute. 2018. Disponível em: https://igarape.org.br/wp-content/ uploads/2018/04/Policy-Brief-Gender-and-Mediation-in-Guinea-Bissau-The-Group-of-Women-Facilitators.pdf. Acesso em: 17 mar. 2020.

AGGESTAM, K.; TOWNS, A. Introduction: The Study of Gender, Diplomacy and Negotiation. In: AGGESTAM, K.; TOWNS, A. Gendering Diplomacy and International Negotiation. Cham: Palgrave Macmillan, 2018. Cap. 1, p. 65-85. AGGESTAM, K.; TOWNS, A. The gender turn in diplomacy: a new research agenda. International Feminist Journal of Politics, v. 21, n. 1, p. 9-28, 2019.

AMADIUME, I. Re-Inventing Africa: Matriarchy, Religion and Culture. Londres: Zed Books, 1997.

BALBINO, V. R. Diplomata. Substantivo Comum de Dois Gêneros. Brasília: Funag, 2011.

BALLESTRIN, L. M. de A. Feminismos subalternos. Estudos Feministas, Florianópolis, v. 25, n. 3, p. 1035-1054, 2017.

CASSIDY, J. A. Gender and Diplomacy. Londres: Routledge, 2017. 
COSTA, P. M. Descriçáo fonológica do crioulo Guineense. 2014. Dissertação (Mestrado em Linguística) - Centro de Artes e Comunicação, Universidade Federal de Pernambuco, Recife, 2014.

DAVIS, A. Mulheres, raça e classe. São Paulo: Boitempo, 2016.

FIGUEIREDO, A.; GOMES, P G. Para além dos feminismos: uma experiência comparada entre Guiné-Bissau e Brasil. Estudos Feministas, Florianópolis, v. 24, n. 3, p. 909-927, 2016.

FRASER, N. Mapeando a imaginaçáo feminista: da redistribuição ao reconhecimento e à representação. Estudos Feministas, Florianópolis, v. 15, n. 2, p. 291-308, 2007.

FRIAÇA, G. J. R. Mulheres Diplomatas no Itamaraty (1918-2011). Brasília: Funag, 2012.

FRITSCHE, C. Opportunities and Challenges for Women in Diplomacy. 2002. Disponível em https://lisd.princeton.edu/sites/lisd2017/files/Fritsche_Lecture.pdf. Acesso em: 7 nov. 2019.

GARCIA, C. C. Breve História do Feminismo. São Paulo: Claridade, 2011.

GOMES, P. A G. "As outras vozes": Percursos femininos, cultura política e processos emancipatórios na Guiné-Bissau. Odeere: Revista do Programa de Pós-Graduação em Relaçôes Étnicas e Contemporaneidade, v. 1, n. 1, p. 121-145, 2016.

HAWKESWORTH, M.; DISCH, L. Introduction. Feminist Theory: Transforming the Known World. In: HAWKESWORTH, M.; DISCH, L. The Oxford Handbook of Feminist Theory. Oxford: Oxford University Press, 2018. Introduction, p.1-15.

HILL COLLINS, P. Pensamento feminista negro. São Paulo: Boitempo, 2019.

HOOKS, B. Olhares Negros: Raça e Representação. São Paulo: Elefante, 2019.

INSTITUTO NACIONAL DE ESTATÍSTICA DE GUINÉ-BISSAU (INEGB). Boletim Estatístico da Guiné-Bissau: Guiné-Bissau em Números 2017. 2017. Disponível em: http://www.stat-guinebissau.com/publicacao/guinebissau-em-numero2017.pdf. Acesso em: 17 mar. 2020.

MARTINS, L. V.; LANDIM, R.; SILVA, A. M. da; IMBASSA, L. Relatório sobre a Situaçáo dos Direitos Humanos na Guiné-Bissau 2010-2012. Bissau: Liga Guineense dos Direitos Humanos, 2013.

MENDOZA, B. Coloniality of Gender and Power: From Postcoloniality to Decoloniality. In: DISCH, L.; HAWKESWORTH, M. The Oxford Handbook of Feminist Theory. Oxford: Oxford University Press, 2018. Cap. 5, p.100-121.
MONTE, I. X. O debate e os debates: abordagens feministas para as relaçôes internacionais. Estudos Feministas, Florianópolis, v. 21, n. 1, p. 59-80, 2013.

NEVES, J. Ideologia, Ciência e Povo em Amílcar Cabral. História, Ciências, Saúde: Manguinhos, Rio de Janeiro, vol. 24, n. 2, p. 333-347, 2017.

NIKLASSON, B.; ROBERTSON, F. The Swedish MFA: Ready to Live Up to Expectations? In: AGGESTAM, K.; TOWNS, A. Gendering Diplomacy and International Negotiation. Cham: Palgrave Macmillan, 2018. Cap. 4, p. 1-22.

OKOME, M. O. What Women, Whose Development? A Critical Analysis Of Reformist Evangelism on African Women. In: OYEWÜMI, O. African Women \& Feminism. Trenton: Africa World Press, 2003. Cap. 4, p. 67-98.

OYEWÜMI, O. Introduction: Feminism, Sisterhood, and Other Foreign Relations. In: OYEWÜMI, O. African Women \& Feminism. Trenton: Africa World Press, 2003. Cap. 1, p. 1-24.

PHILLIPS, A. O que há de errado com a democracia liberal? Revista Brasileira de Ciência Política, n. 6, p. 339- 363, 2011.

SILVA, A. M. da; CORREIA, C.; MARTINS, L. V.; TURÉ, B.; CABRAL, Y. Relatório sobre a Situaçáo dos Direitos Humanos na Guiné-Bissau 2013-2015. Bissau: Liga Guineense dos Direitos Humanos, 2016.

SPIVAK, G. C. Pode o subalterno falar? Belo Horizonte: Editora UFMG, 2012.

TAIWO, O. Feminism and Africa: Reflections on the Poverty of Theory. In: OYEWÜMI, O. African Women \& Feminism. Trenton: Africa World Press, 2003. Cap. 3, p. 45-65.

TICKNER, J. A. Feminist Perspectives on International Relations. In: CARLSNAES, W.; RISSE, T.; SIMMONS, B. A. Handbook of International Relations. Londres: SAGE Publications Ltd, 2006. Cap. 14, p. 275-291.

YOUNG, I. M. Inclusion and Democracy. Oxford: Oxford University Press, 2000.

ZALEWSKI, Marysia. Where is Woman in International Relations? "To Return as a Woman and Be Heard". Millennium: Journal of International Studies, Londres, v. 27, n. 4, p. $847-$ 867,1998 .

ZERILLI, L. Feminist Theory and the Canon of Political Thought. In: DRYZEK, J. S.; HONIG, B.; PHILLIPS, A. The Oxford Handbook of Political Theory. Oxford: Oxford University Press, 2006. Cap. 5, p.106-124. 